\title{
THE EFFECT OF INTRA-ARTICULAR APPLICATION OF ALLOGENIC MESENCHYMAL STEM CELL COMBINE WITH VEGF TO GRAFT TUNNEL HEALING AND AUTOGRAFT TENDON INTEGRATION IN ACL RECONSTRUCTION; A BIOMECHANICAL STUDY
}

\author{
Ferdiansis $^{1}$, Ferdiansyah ${ }^{1}$, Yunus $^{1}$, Fedik Abdul Rantam ${ }^{2}$ \\ ${ }^{1}$ Faculty of Medicine, Airlangga University Surabaya, East Java, Indonesia \\ ${ }^{2}$ Stem Cell Research and Development Center, Universitas Airlangga Surabaya, East Java, Indonesia.
}

\begin{abstract}
Graft-tunnel healing is the most determination factors in successful of Anterior Cruciate Ligament (ACL) reconstruction. The application of bone marrow derived mesenchymal stem cell (MSC) and vascular endothelial growth factor (VEGF) are one of integration biological augmentation method that often used in ACL reconstruction. Combination intra-articular post ACL reconstruction is expected to accelerate healing time and integration strength of tendon graft that used in bone tunnel. This method is experimental laboratory using animal model. The research is randomized post test only controlled group design. Five New Zealand white rabbit knee are used for ACL reconstruction with harmstring tendon graft and treated with combination allograft MSC and VEGF intra-articular, while five other rabbit knee as control without treatment. The evaluation is tensile test in third and six weeks post operation. Data was analyzed statistically and comparatively to compare the influence of MSC and VEGF to integration strength of graft tunnel healing. All the samples from treatment and control group found no complication after surgery. On third weeks evaluation, found a difference in failure tension load in both groups but not statistically significant ( $p>0,05)$, while on six weeks evaluation, found a statistically significant difference. Treatment group has a failure tension load higher than control group. While failure type of ACL tendon graft on 3 weeks evaluation, only 2 of 5 graft have pullout failure in treatment group. However, at three weeks in control group, the failure type of the tendon graft was a midsubtance rupture in intra-articular part during biomechanical tension test. The use of BM-MSC and VEGF intra-articular can increase tension failure load. It is expected that combination of BM-MSC and VEGF can increase integration process between bone graft and healing post ACL reconstruction, so that rehabilitation and mobilisation can be done earlier.
\end{abstract}

Keywords: Graft-tunnel healing, ACL reconstruction, Vascular Endothelial Growth Factor (VEGF), Bone Marrow Derived Mesenchymal Stem Cell (BMMSC)

\section{INTRODUCTION}

Integration of Anterior Cruciatum Ligament (ACL) in bone tunnel is one of the decisive factors for successful reconstruction.
The type of graft used also influences to the length of time required for integration of the bone tendon surface (Bonasia and Amendola, 2012). The important thing that remains of 
concern in ACL reconstruction to widening of the tunnel. This process occurs to be expected for two reasons, the presence of micro-motion and the extravasation of synovial fluid into the bone tunnel (Chen, 2009; Fuchs et al., 2007). The next question, whether the existence of the healing process with fibrotic tissue and the widening of the tunnel allows the process of post-operative early rehabilitation. The ACL post-operative rehabilitation program requires limited mobilization to provide sufficient opportunities for integrated graft within the bone tunnel (Lim et al., 2004). Mesenchymal stem cell has been assessed to have the potential to improve the integration between tendon graft and bone tunnel. This has been widely studied, especially at the experimental level. Several studies have suggested that histology and biomechanical, a soft tissue graft augmentation technique using mesechymal stem cells has different results with most other augmentation techniques (Baxter et al., 2010; Lim et al., 2004; Zelle et al., 2005 ). Histologically, the tissue formed at the border contact surface of the tendon graft and bone wall of the bone tunnel resembles the healing of the bone-tendon-bone graft in reconstruction of ACL (Baxter et al., 2010; Lim et al., 2004; Bonasia and Amendola, 2012). Another study says, the histological picture of integration that occurs resembles the chondral enthesis of native ACL insertions (Lim et al., 2004). In addition, biomechanics mentioned that augmented graft tendon with mesenchymal stem cell has a higher failure limit on load when compared with other augmentation methods (Baxter et al., 2010; Lim et al., 2004).

Bone marrow derived mesenchymal stem cells (BMSCs) are a new source of cells to help accelerate the healing and regeneration of new tissues. BMSCs are able to differentiate into osteoblasts that will form cartilages to form fibrocartilage tissue. Fibrocartilage resembles healing in the bone-tendon-bone graft (Bonasia and Amendala, 2012; Lim et al., 2004). Biomechanical studies have also resulted that the healing of fibrocartilage in the bone-tendon-bone graft gives better results than fibrocollagen healing in soft tissue graft (Bonasia and Amendala, 2012; Ho et al., 2002). Furthermore, histologically, fibrocartilage healing may provide an image resembling chondral enthesis in normal native ACL insertions (Bonasia and Amendala, 2012; Lim et al., 2004). Vascular endothelial growth factor (VEGF) is one of potent angiogenesis mediators, mainly involving the process of activation, migration, and proliferation of endothelial cells in a variety of pathological conditions. One of the problems with the ACL reconstruction process is the occurrence of hypoxia in tendon tissue after transplantation. These conditions cause the occurrence of hypocellular conditions and early degeneration so that the risk of rupture and elongation of the structure of the tendon graft. In a study in Japan, VEGF proved to increase vascularization and improve the integration of fibroblast tissue that exists between the tendon graft and the bone tunnel wall (Tohyama, 2009). 
In accordance with those problems identified above, this study was conducted with the intent to determine the role of bone marrow mesenchymal stem cells and vascular endothelial growth factor intraarticularly in improving the biomechanical strength of graft tendon graft and postoperative graft-tunnel healing after ACL reconstruction in New Zealand white rabbit.

\section{METHODS}

The design of this study was laboratory experimental using animal trial. The research design used was randomized post test only controlled group design. The experimental unit in this study is New Zealand white rabbit (Oryctolagus cuniculus) male, with the weight range 2000-3000g. The control group received treatment in ACL reconstruction using hamstring tendon autograft. While, the treatment group received treatment using hamstring tendon autograft with allogenic bone marrow derived mesenchymal stem cells and vascular endothelial growth factor intraarticular.

ACL reconstruction measures were carried out in both groups. Rabbits prepared and performed anesthesia using a mix of ketamine and xylazin, then shaved $5 \mathrm{~cm}$ in the knee using razor. An anterior incision approach deeply layer by layer until the intra-articular knee joint visible. ACL identification and excision performed on the femoral and intraarticular tibial side, then identification and extraction of the hamstring tendon along a minimum of $3 \mathrm{~cm}$. Preparation by fixing both ends with ethibond 4.0 thread, then tunneling on the tibial side by using an electric drill with $\mathrm{k}$-wire diameter $1.8 \mathrm{~mm}$. On the tibial side, drilling from the infero-lateral to the superomedial is performed. On the femoral side, drilling of the intra-articular in the same direction is performed, then insertion of the prepared tendon graft. The minimum insertion on the tunnel is $1 \mathrm{~cm}$, and at both ends fixed on the periosteum of each bone. In the treatment group, additional treatment of bone marrow derived allograft stem cell and vascular endothelial growth factor with a dose of $300 \mathrm{~g}$ which has been prepared before, the last surgical closed layer by layer until the skin. Evaluation was performed in the form of biomechanics test at 3 weeks and 6 weeks. Samples from the two groups were terminated and preparation was continued with the biomechanical test process.

\section{RESULTS}

Biomechanical tests performed on the rabbit knee endurance post-reconstruction of ACL in this study include the anterior posterior translation measurement and ultimate tension strength measurement. In the ultimate tension strength biomechanics test, the tensile strength data used, also observed the type of damage to the tendon graft that occurs due to the pull. In the translation test the results obtained are as follows: 
Table 1. Results of posterior anterior posterior translation measurements at various angles

\begin{tabular}{|c|c|c|c|c|}
\hline \multirow[t]{2}{*}{ Group } & \multirow[t]{2}{*}{ Unit Exp } & \multicolumn{3}{|c|}{$\begin{array}{c}\text { Translasi Anterior - Posterio } \\
(\mathrm{mm})\end{array}$} \\
\hline & & $30^{\circ}$ & $60^{\circ}$ & $90^{\circ}$ \\
\hline \multirow{6}{*}{ Control 3 weeks } & K3.1 & 1 & 2 & 2 \\
\hline & K3.2 & 3 & 2 & 2 \\
\hline & K3.3 & 3 & 3 & 5 \\
\hline & K3.4 & 3 & 3 & 3 \\
\hline & K3.5 & 3 & 4 & 4 \\
\hline & K3.6 & 2 & 4 & 5 \\
\hline \multirow[t]{6}{*}{ Control 6 weeks } & K6.1 & 2 & 3 & 4 \\
\hline & K6.2 & 3 & 4 & 3 \\
\hline & K6.3 & 4 & 3 & 3 \\
\hline & K6.4 & 2 & 3 & 4 \\
\hline & K6.5 & 2 & 6 & 7 \\
\hline & K6.6 & 1 & 4 & 3 \\
\hline \multirow[t]{6}{*}{ Treatment 3 weeks } & $\mathrm{P} 3.1$ & 4 & 6 & 8 \\
\hline & $\mathrm{P} 3.2$ & 1 & 2 & 3 \\
\hline & P3.3 & 1 & 3 & 4 \\
\hline & P3.4 & 1 & 2 & 5 \\
\hline & $\mathrm{P} 3.5$ & 2 & 3 & 4 \\
\hline & P3.6 & 2 & 4 & 6 \\
\hline \multirow[t]{6}{*}{ Treatment 6 weeks } & $\mathrm{P} 1.1$ & 2 & 4 & 3 \\
\hline & $\mathrm{P} 1.2$ & 2 & 3 & 2 \\
\hline & $\mathrm{P} 1.3$ & 3 & 4 & 3 \\
\hline & $\mathrm{P} 1.4$ & 2 & 2 & 3 \\
\hline & $\mathrm{P} 1.5$ & 2 & 2 & 2 \\
\hline & P1.6 & 2 & 3 & 2 \\
\hline
\end{tabular}

From the raw data, calculation of mean and translational distance that occurs in both standard deviation of the anterior-posterior groups. The results are as follows:

Table 2. Results of mean posterior anterior posterior translation at various angles

\begin{tabular}{|c|c|c|c|c|c|}
\hline Group & Period & $\begin{array}{c}\text { Translational } \\
\text { Angle }\end{array}$ & $\mathrm{N}$ & Mean & Std. \\
\hline \multirow{6}{*}{ Control } & \multirow[t]{3}{*}{3 weeks } & $30^{\circ}$ & \multirow[t]{3}{*}{6} & 2.50 & 0.837 \\
\hline & & $60^{\circ}$ & & 3.00 & 0.894 \\
\hline & & $90^{\circ}$ & & 3.50 & 1.378 \\
\hline & \multirow[t]{3}{*}{6 weeks } & $30^{\circ}$ & \multirow[t]{3}{*}{6} & 2.33 & 1.033 \\
\hline & & $60^{\circ}$ & & 3.83 & 1.169 \\
\hline & & $90^{\circ}$ & & 4.00 & 1.549 \\
\hline \multirow{6}{*}{ Treatment } & \multirow[t]{3}{*}{3 weeks } & $30^{\circ}$ & \multirow[t]{3}{*}{6} & 1.83 & 1.169 \\
\hline & & $60^{\circ}$ & & 3.33 & 1.506 \\
\hline & & $90^{\circ}$ & & 5.00 & 1.789 \\
\hline & \multirow[t]{3}{*}{6 weeks } & $30^{\circ}$ & \multirow[t]{3}{*}{6} & 2.17 & 0.408 \\
\hline & & $60^{\circ}$ & & 3.00 & 0.894 \\
\hline & & $90^{\circ}$ & & 2.50 & 0.548 \\
\hline
\end{tabular}


To perform a statistic analysis in both groups at 3 weeks and 6 weeks, a comparative test of two sample groups were required. Comparative test was performed using Mann-
Whitney test method (comparability test of numerical variables of two unpaired groups). This test is used because of abnormal data distribution according to Shapiro-Wilk test.

Table 3. Test results of normality of data distribution mean posterior anterior posterior translation at various angles.

\begin{tabular}{|c|c|c|c|c|c|c|}
\hline \multicolumn{7}{|c|}{ Tests of Normality } \\
\hline \multirow{2}{*}{ Group } & \multicolumn{3}{|c|}{ Kolmogorov-Smirnov ${ }^{a}$} & \multicolumn{3}{|c|}{ Shapiro-Wilk } \\
\hline & Statistic & df & Sig. & Statistic & df & Sig. \\
\hline \multirow{4}{*}{$\begin{aligned} \text { Translation } 30 \mathrm{deg} & \text { control } 3 \text { weeks } \\
& \text { control } 6 \text { weeks } \\
& \text { treatment } 3 \text { weeks } \\
& \text { treatment } 6 \text { weeks }\end{aligned}$} & .392 & 6 & .004 & .701 & 6 & .006 \\
\hline & .293 & 6 & .117 & .915 & 6 & .473 \\
\hline & .277 & 6 & .168 & .773 & 6 & .033 \\
\hline & .492 & 6 & .000 & .496 & 6 & .000 \\
\hline \multirow{4}{*}{$\begin{array}{ll}\text { Translation } 60 \text { deg } & \text { control } 3 \text { weeks } \\
& \text { control } 6 \text { weeks } \\
& \text { treatment } 3 \text { weeks } \\
& \text { treatment } 6 \text { weeks }\end{array}$} & .202 & 6 & $.200^{*}$ & .853 & 6 & .167 \\
\hline & .277 & 6 & .168 & .773 & 6 & .033 \\
\hline & .254 & 6 & $.200^{\pi}$ & .866 & 6 & .212 \\
\hline & .202 & 6 & $.200^{*}$ & .853 & 6 & .167 \\
\hline \multirow{4}{*}{$\begin{aligned} \text { Translation } 90 \text { deg } & \text { control } 3 \text { weeks } \\
& \text { control } 6 \text { weeks } \\
& \text { treatment } 3 \text { weeks } \\
& \text { treatment } 6 \text { weeks }\end{aligned}$} & .195 & 6 & $200^{\pi}$ & .861 & 6 & .191 \\
\hline & .333 & 6 & .036 & .721 & 6 & .010 \\
\hline & .212 & 6 & $.200^{*}$ & .933 & 6 & .607 \\
\hline & .319 & 6 & .056 & .683 & 6 & .004 \\
\hline
\end{tabular}

The result $p>0.05$ from the Shapiro-Wilk test in the normality test is determined that the data distribution was abnormal, so the comparative test used is Mann-Whitney test was performed. The results are as follows:

Table 4. Mann-Whitney test results for comparative mean posterior anterior posterior translation at evaluation time 3 weeks

Test Statistics $^{a}$

\begin{tabular}{|l|r|r|r|}
\hline & \multicolumn{1}{c|}{$\begin{array}{c}\text { Translation } \\
30 \mathrm{deg}\end{array}$} & $\begin{array}{c}\text { Translation } \\
60 \mathrm{deg}\end{array}$ & \multicolumn{1}{c|}{$\begin{array}{c}\text { Translation } \\
90 \mathrm{deg}\end{array}$} \\
\hline Mann-Whitney U & 10.500 & 17.000 & 9.500 \\
Wilcoxon W & 31.500 & 38.000 & 30.500 \\
Z & -1.255 & -.167 & -1.386 \\
Asymp. Sig. (2-tailed) & .210 & .867 & .166 \\
Exact Sig. [2*(1-tailed & $.240^{\mathrm{b}}$ & $.937^{\mathrm{b}}$ & $.180^{\mathrm{b}}$ \\
\hline Sig.)] & & & \\
\hline
\end{tabular}

a. Grouping Variable: group

b. Not corrected for ties. 
From the results of Mann-Whitney test above obtained significant difference at 0.21 , 0.867 and 0.166 . Because of the value $p>0.05$ it can be concluded that there was no significant difference between anterior posterior translation between control group and treatment group at 30,60 or 90 degrees angle in 3 weeks post operative evaluation.

Table 5. Mann-Whitney test results for comparative mean posterior anterior posterior translation at evaluation time 6 weeks

Test Statistics $^{\text {a }}$

\begin{tabular}{|l|r|r|r|}
\hline & $\begin{array}{c}\text { Translation } \\
\text { 30 deg }\end{array}$ & $\begin{array}{c}\text { Translation } \\
60 \mathrm{deg}\end{array}$ & \multicolumn{1}{c|}{$\begin{array}{c}\text { Translation } \\
90 \mathrm{deg}\end{array}$} \\
\hline Mann-Whitney U & 17.000 & 11.000 & 4.500 \\
Wilcoxon W & 38.000 & 32.000 & 25.500 \\
Z & -.191 & -1.187 & -2.331 \\
Asymp. Sig. (2-tailed) & .849 & .235 & .020 \\
Exact Sig. [2*(1-tailed & $.937^{\mathrm{b}}$ & $.310^{\mathrm{b}}$ & $.026^{\mathrm{b}}$ \\
Sig.)] & & & \\
\hline
\end{tabular}

a. Grouping Variable: group

b. Not corrected for ties.

While in the Mann-Whitney test at 6 weeks, the results obtained significant difference at $0.849,0.235$ and 0.020 . AP translational distance at angle 30 and 60 degree found no significant difference between treatment and control group ( $>0.05)$. However there was a significant difference in AP translation distance at 90 degree knee angle between control and treatment group (significancy $0.020, \mathrm{p}<0.05$ ). Biomechanics test ultimate tension strength results from postreconstruction ACL graft tendon using Shimadzu AG10TE autograph tool with 10 $\mathrm{mm} / \mathrm{min}$ test speed configuration, chart ratio $10,100 \mathrm{~mm} /$ hour chart speed. 
Table 6. Ultimate tension strength measurement results and types of damage occurring in tendon graft during evaluation period 3 and 6 weeks

\begin{tabular}{|c|c|c|c|c|}
\hline Group & Evaluation & Unit & Ultimate & Type \\
\hline \multirow[t]{11}{*}{ Control } & \multirow[t]{5}{*}{3 weeks } & $\begin{array}{l}\text { K3.1 } \\
\text { K3.2 } \\
\end{array}$ & $\begin{array}{l}0.027 \\
0.012\end{array}$ & $\begin{array}{l}\text { Ruptur } \\
\text { Ruptur }\end{array}$ \\
\hline & & K3.3 & 0.036 & Ruptur \\
\hline & & K3.4 & 0.010 & Ruptur \\
\hline & & K3.5 & 0.012 & Ruptur \\
\hline & & K3.6 & 0.021 & Ruptur \\
\hline & \multirow[t]{6}{*}{6 weeks } & K6.1 & 0.042 & Ruptur \\
\hline & & K6.2 & 0.038 & Ruptur \\
\hline & & K6.3 & 0.035 & Ruptur \\
\hline & & K6.4 & 0.041 & Ruptur \\
\hline & & K6.5 & 0.067 & Ruptur \\
\hline & & K6.6 & 0.050 & Ruptur \\
\hline \multirow[t]{12}{*}{ Treatment } & \multirow[t]{6}{*}{3 weeks } & P3.1 & 0.027 & Ruptur \\
\hline & & P3.2 & 0.012 & Pullout \\
\hline & & P3.3 & 0.019 & Ruptur \\
\hline & & P3.4 & 0.027 & Ruptur \\
\hline & & P3.5 & 0.013 & Ruptur \\
\hline & & P3.6 & 0.012 & Pullout \\
\hline & \multirow[t]{6}{*}{6 weeks } & P1.1 & 0.057 & Ruptur \\
\hline & & $\mathrm{P} 1.2$ & 0.075 & Ruptur \\
\hline & & $\mathrm{P} 1.3$ & 0.055 & Ruptur \\
\hline & & P1.4 & 0.083 & Ruptur \\
\hline & & P1.5 & 0.082 & Ruptur \\
\hline & & P1.6 & 0.067 & Ruptur \\
\hline
\end{tabular}

From the data of ultimate tension strength measurement above, the following analysis

Table 7. The mean value of ultimate tension strength in both groups during evaluation at 3 weeks and 6 weeks

\begin{tabular}{|c|l|l|l|l|}
\hline Group & Period & $\mathrm{N}$ & \multicolumn{1}{|c|}{ Mean } & Std. \\
\hline \multirow{2}{*}{ Control } & 3 weeks & 6 & 0.0197 & 0.010 \\
\cline { 2 - 5 } & 6 weeks & 6 & 0.046 & 0.012 \\
\hline \multirow{2}{*}{ Treatment } & 3 weeks & 6 & 0.018 & 0.007 \\
\cline { 2 - 5 } & 6 weeks & 6 & 0.0698 & 0.012 \\
\hline
\end{tabular}

After obtaining the mean and standard intersection of each group, analyzed whether the distribution of normal data or not by using the Shapiro-Wilk test. The results are as follows 
Table 8. Ultimate tension strength / pullout strength test results from both groups at 3 weeks and 6 weeks evaluation

\begin{tabular}{|ll|r|r|r|r|r|r|}
\hline \multicolumn{1}{|c|}{ Tests of Normality } \\
\hline \multirow{2}{*}{ Group } & \multicolumn{2}{|c|}{ Kolmogorov-Smirnov } & \multicolumn{3}{c|}{ Shapiro-Wilk } \\
\cline { 2 - 8 } & Statistic & \multicolumn{1}{c|}{ df } & \multicolumn{1}{c|}{ Sig. } & Statistic & \multicolumn{1}{c|}{ df } & Sig. \\
\hline pull out strenght & control 3 weeeks & .271 & 6 & .191 & .885 & 6 & .291 \\
& control 6 weeks & .284 & 6 & .140 & .847 & 6 & .150 \\
& treatment 3 weeks & .271 & 6 & .194 & .798 & 6 & .056 \\
& treatment 6 weeks & .187 & 6 & $.200^{*}$ & .893 & 6 & .337 \\
\hline
\end{tabular}

a. Lilliefors Significance Correction

*. This is a lower bound of the true significance.

From the results of Shapiro-Wilk test obtained significant value at $0.291,0.150$, 0.058 and 0.337 . Because of the value $p>0.05$ it can be concluded that the distribution data

Table 9. Independent $\mathrm{T}$ test results comparing the average ultimate tension strength score between two groups in 3 weeks evaluation

Group Statistics

\begin{tabular}{|c|c|c|c|c|c|}
\hline & Group & $\mathrm{N}$ & Mean & $\begin{array}{l}\text { Std. } \\
\text { Deviation }\end{array}$ & $\begin{array}{l}\text { Std. Error } \\
\text { Mean }\end{array}$ \\
\hline $\begin{array}{l}\text { pull out } \\
\text { strenght }\end{array}$ & $\begin{array}{l}\text { control } 3 \text { weeeks } \\
\text { treatment } 3 \text { weeks }\end{array}$ & $\begin{array}{l}6 \\
6\end{array}$ & $\begin{array}{l}.01967 \\
.01833\end{array}$ & $\begin{array}{l}.010328 \\
.007202\end{array}$ & $\begin{array}{l}.004216 \\
.002940\end{array}$ \\
\hline
\end{tabular}

Independent Samples Test

\begin{tabular}{|c|c|c|c|c|c|c|c|c|c|c|}
\hline & \multicolumn{2}{|c|}{$\begin{array}{l}\text { Levene's Test } \\
\text { for Equality } \\
\text { of Variances }\end{array}$} & \multicolumn{7}{|c|}{ t-test for Equality of Means } \\
\hline & & \multirow[b]{2}{*}{$\mathrm{F}$} & \multirow[b]{2}{*}{ Sig. } & \multirow[b]{2}{*}{$\mathrm{t}$} & \multirow[b]{2}{*}{ df } & \multirow[b]{2}{*}{$\begin{array}{l}\text { Sig. } \\
(2- \\
\text { tailed }) \\
\end{array}$} & \multirow[b]{2}{*}{$\begin{array}{l}\text { Mean } \\
\text { Difference }\end{array}$} & \multirow[b]{2}{*}{$\begin{array}{l}\text { Std. Error } \\
\text { Difference }\end{array}$} & \multicolumn{2}{|c|}{$\begin{array}{l}95 \% \text { Confidence } \\
\text { Interval of the } \\
\text { Difference }\end{array}$} \\
\hline & & & & & & & & & Lower & Upper \\
\hline $\begin{array}{l}\text { pull out } \\
\text { strenght }\end{array}$ & $\begin{array}{l}\text { Equal } \\
\text { variances } \\
\text { assumed }\end{array}$ & 1.021 & .336 & .259 & 10 & .801 & $.0 p 1333$ & .005140 & -.010120 & .012787 \\
\hline & $\begin{array}{l}\text { Equal } \\
\text { variances } \\
\text { not } \\
\text { assumed }\end{array}$ & & & .259 & 8.933 & .801 & .001333 & .005140 & -.010308 & .012975 \\
\hline
\end{tabular}


For comparison in control group and treatment group at 3 weeks evaluation, the result of significancy is 0.801 . Because $p>0.05$ it can be concluded that there is no significant difference between pullout strength / ultimate tension strength in control and treatment group at 3 weeks post-operation. While at 6 weeks, the following results were obtained:

Table 10. Independent $\mathrm{T}$ test results comparing the average ultimate tension strength score between two groups in 6 weeks evaluation

\section{Group Statistics}

\begin{tabular}{|ll|l|l|l|l|}
\hline & Group & N & Mean & $\begin{array}{l}\text { Std. } \\
\text { Deviation }\end{array}$ & $\begin{array}{l}\text { Std. Error } \\
\text { Mean }\end{array}$ \\
\hline $\begin{array}{l}\text { pull out } \\
\text { strenght }\end{array}$ & $\begin{array}{l}\text { control 6 weeeks } \\
\text { treatment 6 weeks }\end{array}$ & 6 & .04550 & .011675 & .004766 \\
& 6 & .06983 & .012172 & .004969 \\
\hline
\end{tabular}

Independent Samples Test

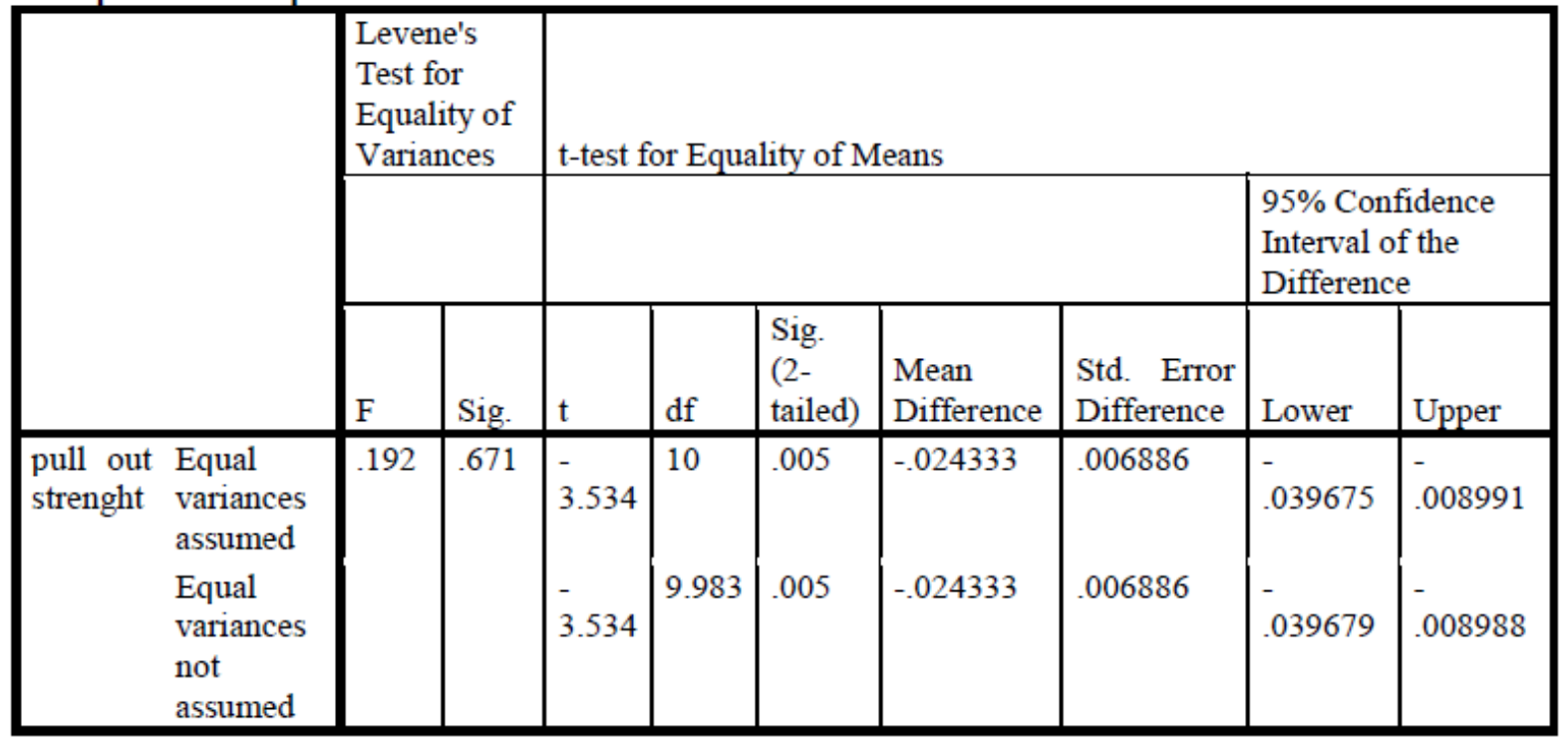

From the results of independent $t$ tests above obtained value significancy 0.005 . Because the $\mathrm{p}$ value $<0.05$ it can be concluded that there is a significant difference between the pullout strength of the treatment group and control group at 6 weeks post-operative observation. In addition to pullout strength also observed the type of damage that occurs in the tendon graft when tested biomechanical pullout strength. The result is as follows: 
Type of damage of the tendon graft in pullout strength test at 3 weeks post-operative

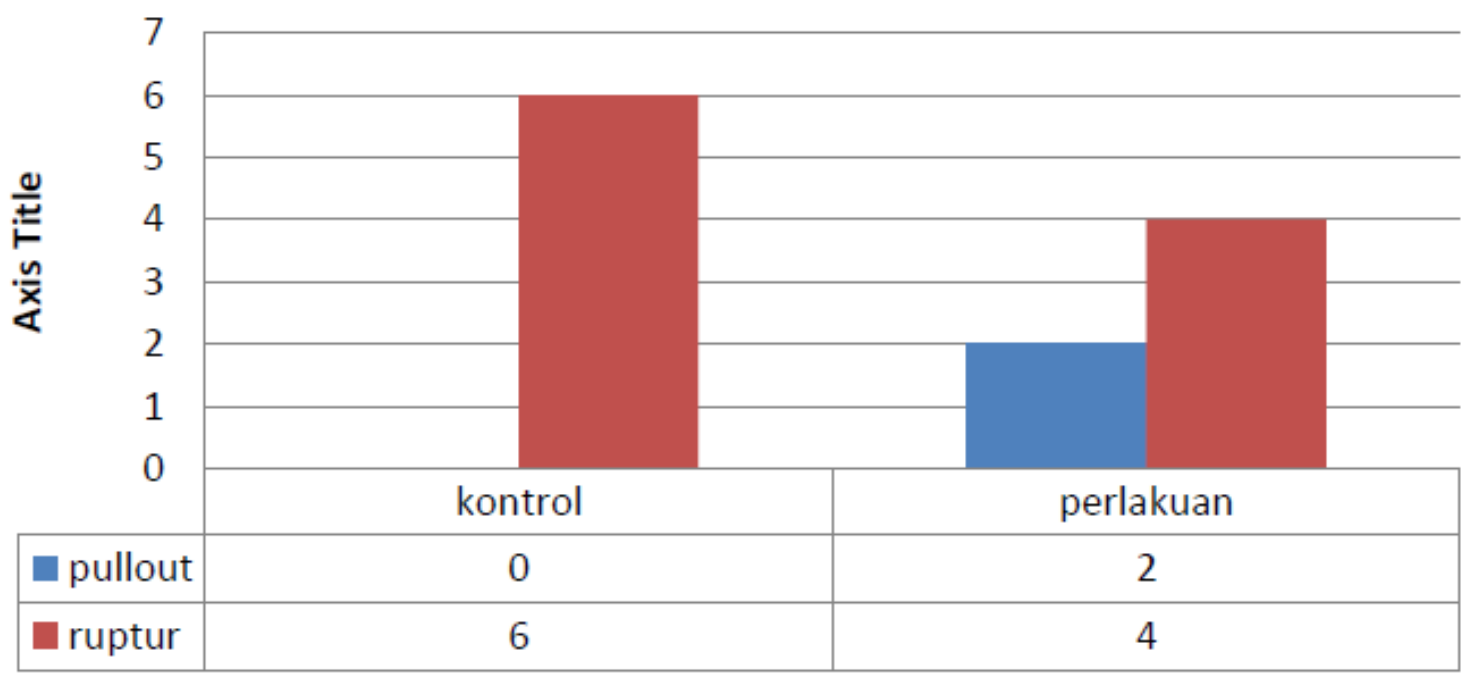

Figure 1. The type of damage of the tendon graft in pullout strength test at 3 weeks post-operative

Type of damage of the tendon graft in pullout strength test at 3 weeks post-operative

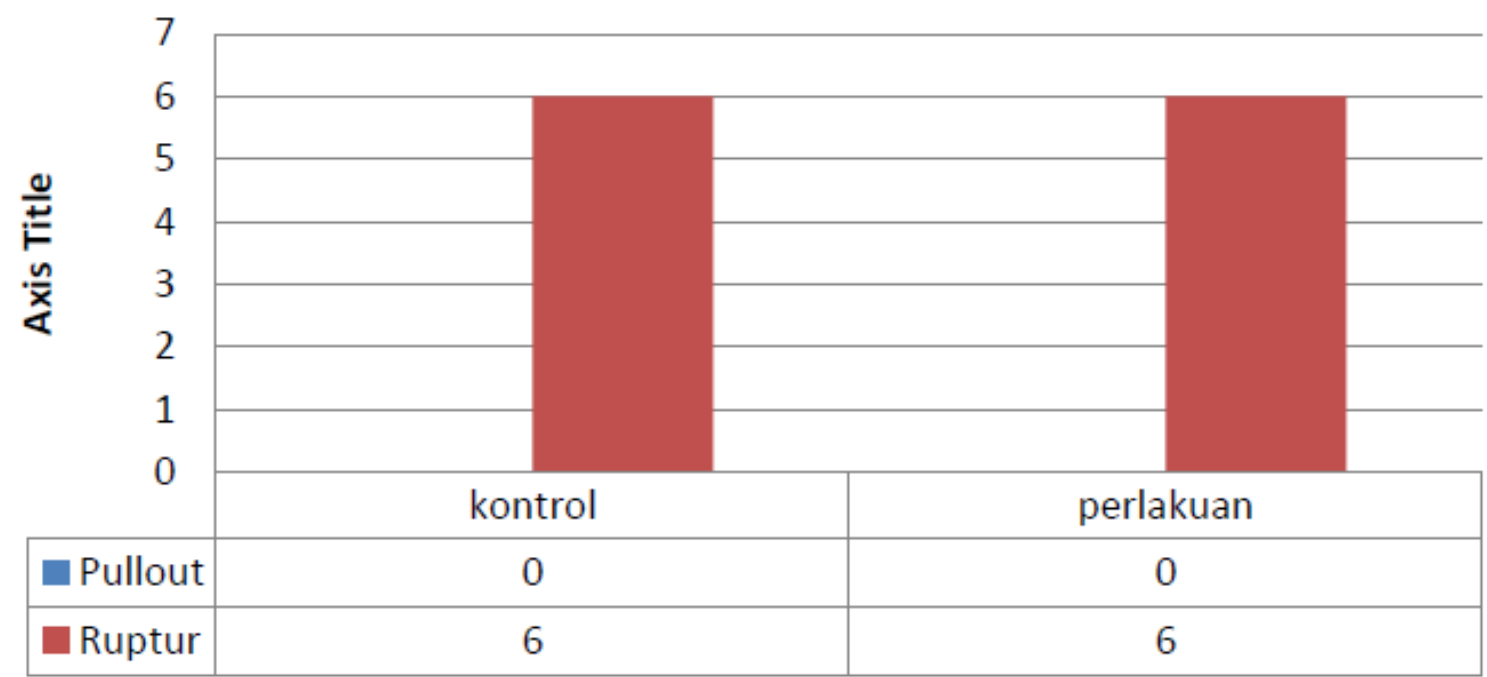

Figure 2. The type of damage of the tendon graft in pullout strength test at 6 weeks post-operative

The biomechanical test was performed at 3 weeks postoperative in control group and 6 tendon graft was ruptured in the intraarticular (midsubstance) $(100 \%)$, while at 3 weeks in treatment group obtained 4 graft tendon rupture on the intra-articular (midsubstance ) 
(66.7\%) and 2 graft tendons having pullout on the bone tunnel of the femur (33.3\%). At 6 weeks control group the overall results of 6 graft tendons were ruptured in midsubstance $(100 \%)$, while in 6 weeks treatment group all the tendons were ruptured on midsubstance during biomechanics testing.

\section{DISCUSSION}

The hamstring tendon has recently become one of the most commonly used graft tendon options for ACL reconstruction (Yamako et al., 2002). One of the considerations is that it is better in strength than some other types of tendon graft and low donor region morbidity. There has been considerate research on various aspects of the use of hamstring tendons as grafts, ranging from engineering, biomechanical, histological and also the outcome of this procedure (Bonasia \& Amendola, 2012)

The success of ACL reconstruction procedure using hamstring as a tendon graft depends not only on the initial fixation when the graft mounting operation performed, but also on the biological integration of the graft in the bone tunnel that determines the long-term outcome. Although many research has been done to study this, the factors that affect the biological integration of the tendon graft in the bone tunnel are still not clearly understood. There have been many studies the effects of supplementation as an augmentation to strengthen or accelerate the process of graft integration within the bone / graft tunnel healing. But in the various materials used, there were not research proves the superiority of a material that significantly exceeds the other additives (Zelle et al. 2005).

Biomechanical testing is one of the most commonly used methods to study the effectiveness of a material used as an augmentation to accelerate or increase the integration strength of tendon graft in bone tunnel. It is because biomechanical tests can provide a description that resembles a clinical condition that occurs in the knee sufferer after ACL reconstruction surgery. Various kinds of biomechanical testing techniques have been conducted and developed. However, the most common type of biomechanical test is the failure tension load or ultimate tension strength test. This test is performed by giving the strain / tension force on the knee so as to provide the strain load on the applied tendon graft. The purpose of this test is to evaluate the strength of integration and healing of the tendon graft within the bone. In addition, it is also to evaluate the strength of tendon structure that is inside the joint. It is hoped that the good quality of healing and integration of tendon graft within the bone tunnel will improve the outcome of ACL reconstruction in both the short and long term.

Yamakado et al., explains that the mechanical stress in the tendon graft used can affect the healing quality and strength of the tendon integration within the bone tunnel. There are differences in histological features that occur in the mouth of the bone tunnel and along the bone tunnel. In the study also explained that the difference is due to the type 
of force that works on the graft of the tendon from the mouth of the tunnel and also along the bone tunnel. It is also mentioned that the position of tendon graft insertion in the bone tunnel also has a role to play in the resulting force and work on the tendon graft. This is particularly important given the various techniques and tunnel positions used in actual ACL reconstruction in humans (Shrive et al. 1995).

In this study, the type of reconstruction performed resembles the ACL reconstruction technique that is common performed in humans. The tendon graft used is also the hamstring tendon autograft of the New Zealand white rabbit. The technique used is open surgery transtibial technique. The type of initial fixation used in the distal femur and proximal tibia as the insertion of the tendon graft is the stitches on the periosteum. This is done only considering the elements of ease of technique and tools. After the procedure, all rabbits in both groups received the same treatment, and did not immobilized.

Biomechanical test conducted in this research is using autograph tool with vertical pull direction. The pulling direction of the biomechanical test performed does not reflect the clinical condition of the ACL reconstructive patient, since the strain / tension force occurring in the knee and the weight of the graft is a combination of various styles. One reason for the selection of vertical strain biomechanical testing techniques in this study is the limitation of the tool that can reflect the direction of the actual strain force. In addition, the purpose of this biomechanical test is to evaluate the integration strength of tendon graft within the bone tunnel and the power of tendon graft itself post-treatment.

One thing that happens to postreconstruction tendon graft is the occurrence of reduced stiffness. This is explained by Tohyama et al., who studied the effects of VEGF on reconstruction of lamb ACL. It was mentioned that the VEGF application on tendon graft decreased the degree of stiffness of the tendon graft itself. In the present study, this phenomenon can be observed by the posterior anterior-posterior translation of the post-operative femur-graft-tibia complex compared between control and treatment groups (Tohyama et al. 2009).

In this study also measured the posterior anterior translational distance of the femurgraft-tibia complex. Measurements and data collection were done at 3 weeks and 6 weeks post-operative. In the 3 weeks evaluation, the mean of anterior-posterior translation results at knee flexion angle of 30 degrees was $2.5 \mathrm{~mm}$ (SD 0.837) in control group and $1.83 \mathrm{~mm}$ (SD 1.169 ) in treatment group. While at 60 degree knee flexion angle, mean mean distance of AP translation of $3 \mathrm{~mm}$ (SD 0.894) in control group and $3.33 \mathrm{~mm}$ (SD 1.506) in treatment group. At a 90 degree angle of flexibility, a 3.5 mm AP translational distance (SD 1.378) and $5 \mathrm{~mm}$ (SD 1.789) was obtained for control group. From the result of measurement test of AP translation distance of various angles (30, $60,90)$ in control and treatment groups, there was a mean difference between two groups. 
The mean results obtained and comparised between two groups using the Mann-Whitney test. There was no statistically significant difference between the translational distance of rabbit knee joint $\mathrm{AP}$ in control and treatment group, with the significancy value 0.21 (30 deg), 0.867 (60 deg) and 0.166 (60 $\operatorname{deg})(\mathrm{p}>0.05)$.

In 6 weeks post-operative evaluation, the mean of AP translation distance at knee flexion angle were 30 degrees: $2.33 \mathrm{~mm}$ (SD 1,033) for control group and $2.17 \mathrm{~mm}$ (SD 0.408 ) for treatment group. While at the 60 degree angle obtained mean of 3.83 (SD 1.169) for control group and 3.00 (SD 0.894) for treatment group. At the angle of knee flexion 90 degrees there was a mean difference of $4 \mathrm{~mm}$ (SD 1.549) for control group and 2.5 $\mathrm{mm}$ (SD 0.548) for treatment group. While in 3 weeks evaluation, the mean results of AP translation distance measurements at these angles were comparable with the MannWhitney test and conclusions were obtained, there was no statistically significant difference between the mean AP translation distance in control and treatment group at the flexion angle 30 (significancy 0.849 ) and 60 degrees (0.235) ( $p>0.05)$. However, there was a statistically significant difference in mean AP translation distance between two groups at knee flexion angle of 90 degrees with significancy $0.02(\mathrm{p}<0.05)$.

From the comparison results, the mean values of AP translation distance measurements at various angles between control and treatment group were found a difference, but not statistically significant, except for the angle measurement of 90 degrees at 6 weeks post-operative. This result is different from previous studies which mention significant differences in the mean AP translation distance between control and treatment group in the form of VEGF (Tohyama et al. 2009). In the study by Tohyama et al., it was mentioned that giving VEGF to the graft tendon causes increased laxity of the tendon graft. However this is mentioned only temporarily at the beginning of postoperative (Tohyama et al. 2009; Pufe et al. 2004). The exact cause of this phenomenon is not yet known for certain but one of the studies that can explain is according to Shrive et al., which shows that at the beginning of postoperative graft tendon histologic features obtained in the form of new vascular formation areas, infiltration of new cells and the formation of new collagen fibers that have not been arranged regularly. The formation of new vascular tissues, cell infiltration and irregular collagen fibers are the "weakness" of the structure of the tendon graft used (Shrive et al. 1995; Pufe et al., 2004). In addition, external VEGF applications also trigger the production of matrix metalloproteinase (MMP) enzyme by several cell types (Ho et al., 2002).

The result of mean comparison of AP translation distance between control and treatment group in this study showed that there was no significant difference except in the treatment group at 90 degree angle at 6 weeks evaluation. These results are generally different from those of previous studies which 
show that the AP translation distance of the VEGF application treatment group has a greater value. This is because of the different types of treatment. In a study conducted by Tohyama et al., The VEGF application was performed on sheep by soaking the tendon graft for 15 minutes (Tohyama et al. 2009). While in this study VEGF applied by intraarticular injection. VEGF application by immersion is a more effective way to infiltrate VEGF throughout the tendon graft tissue when compared with intra-articular single injection. This may create different histologic conditions in tendon graft. While in intra-articular injection, the absorption of VEGF is not very similar so that the structural graft tendon does not give much difference, especially on the level of stiffness / spasticity and laxity between control and treatment group. Ultimate tension strength or maximum stretch strength during strain test is one of the measurements performed in this study. Three weeks postoperative evaluation showed mean $0.0197 \mathrm{KN}$ (SD 0.010) for control group and 0.018 (SD 0.007) for treatment group. While at 6 weeks obtained mean value of $0.046 \mathrm{KN}$ (SD 0.012) for control group and $0.0698 \mathrm{KN}$ (SD 0.012) for treatment group. From this results then performed statistical comparative test using independent $\mathrm{t}$ test. There was no significant difference between mean ultimate tension strength in control and treatment group on 3 weeks evaluation with significancy of 0.801 ( $p>0.05)$. While at 6 weeks evaluation, there was a significant difference between mean ultimate tension strength in control and treatment group with significancy 0.005 (p $<0.05)$.

From these results, it can be analyzed that in the early post-reconstruction phase (3 weeks evaluation), there is no difference in the effect of VEGF and BM-MSC on post-reconstruction ACL graft tendon. This is consistent with the results of a study from Tohyama et al., which showed no significant difference between ultimate tension strength between the tendon groups receiving VEGF and control group. However, in this study, 6 weeks evaluation results showed significant differences in ultimate tension strength in treatment group compared with control group. In control group, the tendon graft underwent ischemic and transient necrosis, but after implantation, normal healing occurs via fibroblast tissue (Zelle et al. 2005). In the bone tunnel, at week 8 , there was a healing stage of tissue growth between the tendon and bone that is more organized with the image of collagen fibers that spread on the border in the direction of the pull of the tendon graft.

At 6 weeks evaluation, the ultimate tension strength difference between two groups actually showed a difference in the strength of tendon graft in general, unable to specifically describe the strength of bone tunnel healing integration. This can be inferred because all of the tendon graft in this group is damaged in midsubstance and no one experiences a pullout. But it can also illustrate that the process of healing and integration of the tendon graft in both groups is not really different. The cause of the difference in mean 
ultimate tension strength in both groups is actually the difference in the midsubstance strength of the tendon graft.

At 3 weeks evaluation, there were two units of tendon graft which experienced pullout. It can occur because the post-operative insial "soft tissue flaws" due to ischemia and necrosis of the tendon tissue during and after transplantation that began to form a new tissue of fibrovascular. Soft tissue flaws that occur appear to be more dominant in the midsubstance part of the tendon graft than those occurring in the graft section within the bone tunnel.

\section{CONCLUSION}

From research on biomechanical studies the effect of intraarticular VEGF and BM-MSC on graft tunnel healing and integration of tendon graft on ACL reconstruction can be summarized as follows:

1. There were no significant differences from the translation distance AP that reflects the level of rigidity/stiffness of tendon graft reconstruction of the ACL between control with the ACL reconstruction plus BM-MSC and VEGF in intra-articular at 3 weeks and 6 weeks post-operative knee fleksion conditions in different angles. Only at a 90 degree angle of flexibility there is a significant difference in AP translational distance that reflects the increased stiffness of the tendon graft receiving VEGF and BM-MSC intraarticularly.
2. Granting of VEGF and BM-MSC in intra-articular give influence on the structural integration of the tendon graft at 6 weeks post-operative. But it still unable to explain whether the granting of VEGF and BM-MSC in intr-articular can provide direct influence on graft healing tunnel in particular, also the influence mechanism of both materials histologically on graft structure of tendon.

\section{REFERENCE}

1. Baxter FR, Bach JS, Detrez F, Cantournet $\mathrm{S}$, Corte L, Cherkaoui M, et al. Augmentation of Bone Tunner Healing in Anterior Cruciate Ligament Grafts : Application of Calcium Phospates and Other Materials. Journal of Tissue Engineering. 2010; 2010: p. 12.

2. Bonasia DE, Amendola A. Graft choice in ACL reconstruction. In The Knee Joint : Surgical Techniques and Strategies.: Springer; 2012. p. 173-181.

3. Chen $\mathrm{CH}$. Strategies to enhance tendon graft - bone healing in anterior cruciate ligament reconstruction. Chang Gung Med J. 2009; 32(5): p. 483-493.

4. Fuchs TF, Petersen W, Vordemvenne T, Stange R, Raschke M, Paletta JRJ. Influence of Synovial Fluid on Human Osteoblasts : an In Vitro Study. The Scientific World Journal. 2007;: p. 20122020. 
5. Ho WP, Liau JJ, Cheng CK. Biomechanical Study of Bone-Patellar Tendon-Bone and Bone-ACL-Bone Grafts. Journal of Medical and Biological Engineering. 2002; 22(2): p. 103-107.

6. Lim JK, Hui J, Li L, Thambyah A, Goh J, Lee EH. Enhancement of Tendon Graft Osteointegration Using Mesenchymal Stem Cells in a Rabbit Model of Anterior Cruciate Ligament Reconstruction. Arthroscopy: The Journal of Arthroscopic and Related Surgery. 2004;: p. 899-910.

7. Pufe T, Harde V, Petersen W, Goldring M, TillMann B, Mentlein R. Vascular endothelial growth factor (VEGF) induces matrix metalloproteinase expression in immortalized chondrocytes. J Pathol. 2004; 202: p. 367-74.

8. Shrive N, Chimich D, Marchuk L, Wilson J, Brant R, Frank C. Soft-tissue "flaws" are associatedwith the material poperties of the healing rabbit medial collateral ligament. J Orthop Res. 1995; 13: p. 923-9.

9. Tohyama H, Yoshikawa T, Ju JY, Yasuda K. Revascularization in the tendon graft following anterior cruciate ligament reconstruction of the knee : Its mechanisms and regulation. Chang Gung Med J. 2009; 32(2): p. 133-139.

10. Yamakado K, Kitaoka $\mathrm{K}$, Yamada $\mathrm{H}$, Hashiba K, Nakamura R, Tomita K. The Influence of Mechanical Stress on Graft Healing in a Bone Tunnel. Arthroscopy : The Journal of Arthroscopic and Related Surgery. 2002; 18(1): p. 82-90.
11.Zelle BA, LatterMann C, Chhabra A, Fu FH, Huard J. Biological Considerations of Tendon Graft Incorporation Within the Bone Tunnel. In Operation Techniques in Orthopaedics.: Elsevier; 2005. p. 36-42.cc 